\title{
A method for near full-length amplification and sequencing for six hepatitis $C$ virus genotypes
}

Rowena A. Bull ${ }^{1 *}$, Auda A. Eltahla1, Chaturaka Rodrigo ${ }^{1}$, Sylvie M. Koekkoek², Melanie Walker, Mehdi R. Pirozyan', Brigid Betz-Stablein ${ }^{1}$, Armin Toepfer ${ }^{4}$, Melissa Laird ${ }^{4}$, Steve $\mathrm{Oh}^{4}{ }^{4}$ Cheryl Heiner ${ }^{4}$, Lisa Maher ${ }^{3}$, Janke Schinkel ${ }^{2}$, Andrew R. Lloyd ${ }^{1}$ and Fabio Luciani ${ }^{1}$

\begin{abstract}
Background: Hepatitis C virus ( $\mathrm{HCV}$ ) is a rapidly evolving RNA virus that has been classified into seven genotypes. All HCV genotypes cause chronic hepatitis, which ultimately leads to liver diseases such as cirrhosis. The genotypes are unevenly distributed across the globe, with genotypes 1 and 3 being the most prevalent. Until recently, molecular epidemiological studies of HCV evolution within the host and at the population level have been limited to the analyses of partial viral genome segments, as it has been technically challenging to amplify and sequence the full-length of the $9.6 \mathrm{~kb} \mathrm{HCV}$ genome. Although recent improvements have been made in full genome sequencing methodologies, these protocols are still either limited to a specific genotype or cost-inefficient.

Results: In this study we describe a genotype-specific protocol for the amplification and sequencing of the nearfull length genome of all six major HCV genotypes. We applied this protocol to $122 \mathrm{HCV}$ positive clinical samples, and had a successful genome amplification rate of $90 \%$, when the viral load was greater than $15,000 \mathrm{IU} / \mathrm{ml}$. The assay was shown to have a detection limit of 1-3 cDNA copies per reaction. The method was tested with both Illumina and PacBio single molecule, real-time (SMRT) sequencing technologies. Illumina sequencing resulted in deep coverage and allowed detection of rare variants as well as HCV co-infection with multiple genotypes. The application of the method with PacBio RS resulted in sequence reads greater than $9 \mathrm{~kb}$ that covered the near fulllength HCV amplicon in a single read and enabled analysis of the near full-length quasispecies.
\end{abstract}

Conclusions: The protocol described herein can be utilised for rapid amplification and sequencing of the near-full length HCV genome in a cost efficient manner suitable for a wide range of applications.

\section{Background}

Hepatitis $\mathrm{C}$ virus (HCV) is a significant human pathogen affecting nearly $3 \%$ of the world's population, and is a leading cause of chronic liver diseases including cirrhosis and hepatocellular carcinoma [1]. HCV is a member of the Flaviviridae family and has a single stranded RNA genome that is $9.6 \mathrm{~kb}$ in length with positive polarity. The genome contains a single open-reading frame and encodes a precursor polyprotein of approximately 3010 amino acid residues. Within an infected cell, this polyprotein is processed by cellular and host proteases to

\footnotetext{
* Correspondence: r.bull@unsw.edu.au

${ }^{1}$ School of Medical Sciences, Faculty of Medicine, University of New South

Wales, Sydney 2052, Australia

Full list of author information is available at the end of the article
}

yield ten structural (core, E1 and E2) and non-structural (p7, NS2, NS3, NS4A, NS4B, NS5A and NS5B) proteins [2]. The viral RNA-dependent RNA polymerase, or $\mathrm{NS} 5 \mathrm{~B}$, is a key enzyme in the HCV replication complex within an infected cell, and is responsible for the production of nascent genomes for packaging into new virions. The polymerase is highly error-prone [3], a feature common to many RNA viruses, and as a result $\mathrm{HCV}$ exists as seven distinct genotypes (GT1-7), which differ by up to $35 \%$ at the nucleotide level [4]. Within each genotype, viruses have been further classified into subtypes (1a, 1b, 1c, etc.) with about $20 \%$ inter-subtype nucleotide divergence [5]. The genotypes are unevenly distributed across the globe, with genotypes 1 and 3 
being the most prevalent [6], and genotype 7 being the rarest having only been detected once in Canada from a Central African immigrant [7].

With the advent of direct-acting antivirals (DAA) for the treatment of $\mathrm{HCV}$ infections, there is a need to monitor the emergence of resistance-associated variants before and after treatment. While testing specific regions of the HCV genome using both consensus and next generation sequencing (NGS) has enabled such monitoring in DAA therapies, including agents targeting NS3, NS5A and NS5B $[8,9]$, the emerging DAA combination regimens emphasise the necessity to simultaneously screen multiple genes of the viral genome in a simple, costeffective manner. Furthermore, there is a need to detect whether individual viral variants carry multiple polymorphisms conferring resistance against all DAAs in a combination regimen, therefore increasing the chances of viral persistence against such therapies. In the past, such analysis was possible only by cloning and consensus sequencing. However, as the NGS technologies continue to improve read length $(20 \mathrm{~kb}$ with PacBio $\mathrm{RS}$ and $300 \mathrm{bp}$ paired-end for Illumina) the range for covariant studies continues to increase.

In addition to monitoring viral variants associated with drug resistance, methods for the molecular amplification and sequencing of HCV RNA have also been instrumental in characterising HCV infections, including studies seeking to understand virus transmission and within-host evolution [10-12]. Previously, these methods focused on specific regions of the HCV genome, or analysed the entire genome in separate fragments, which is laborious, cost-prohibitive and leads to analysis issues, including uneven coverage due to amplicon pooling, artificial recombinants during genome assemby and multiple PCR primer bias. Therefore, there is a need for sensitive methods that can amplify the entire viral genome from all GTs in clinical samples. A few reports have described the amplification of near full-length $\mathrm{HCV}$ genomes, however these were either limited by the sensitivity of the methodology or coverage of all major genotypes [13-15]. Recently, RNA sequencing technology has been applied to sequence HCV in a non-specific manner [15]. While these methods offer the advantage of reduced primer bias and reduced upstream labour, they require increased labour in data analysis, have reduced sensitivity and increased overall cost per sample [15].

Here, we describe a simple method which allows sensitive amplification of near full-length HCV genomes from GT 1 to 6 . Using this method, $90 \%(n=121)$ of a set of HCV-infected clinical samples were successfully amplified and sequenced using an NGS approach. As a proof of principle, the method was also applied to amplify and sequence near full-length HCV genomes from two subjects co-infected with multiple genotypes. The ability to generate near full-length quasispecies sequence was tested with one amplicon using the PacBio RS II platform.

\section{Methods \\ Cohort}

Stored plasma samples positive for HCV GT1, 2, 3 and 6 were made available from the Hepatitis $C$ Incidence and Transmission Study in prisons and community cohort (HITS), which is a prospective cohort of HCV seronegative and HCV RNA negative subjects in New South Wales, Australia [16]. Stored plasma samples positive for HCV GT 4 and 5 were from Academisch Medisch Centrum (AMC) patients identified with $\mathrm{HCV}$ infection. In all subjects, HCV infection was confirmed by detection of HCV-specific antibody and RNA. In the HITS cohort, $\mathrm{HCV}$ antibody testing was performed using the qualitative Abbott ARCHITECT anti-HCV chemiluminescent microparticle immunoassay (Abbott Diagnostics, Abbott Park, IL, USA). For the AMC patients HCV antibody testing was performed using the AxSYM HCV 3.0 serology test (Abbott Laboratories, Abbott Park, IL, USA). For all subjects quantitative HCV RNA detection was performed with the COBAS AmpliPrep/COBAS TaqMan HCV assay (Roche, Branchburg, NJ, USA; lower limit of detection $15 \mathrm{IU} / \mathrm{ml}$ ).

\section{Ethics statement}

For the HITS samples ethical approvals were obtained from Human Research Ethics Committees of Justice Health (reference number GEN 31/05), New South Wales Department of Corrective Services (reference number 05/0884), and the University of New South Wales (reference numbers 05094, 08081), all located in Sydney, Australia. Written informed consent was obtained from the participants. For the Dutch samples, the study was performed according to the Dutch FEDERA code of conduct for responsible use of human tissue and medical research 2011.

\section{Genotyping and detection of multiple infection}

Genotype determination and detection of multiple $\mathrm{HCV}$ genotype infection was performed on a region of the core as previously described [17].

\section{Primer design}

Full-length genome sequences representing each of the six HCV genotypes were downloaded from GenBank and used for primer design. This included 116, 28, 50, 66, 11 and 7 different strains for GTs 1-6 respectively. To choose primer binding sites we manually scanned the $3^{\prime}$ end of the genome for regions $>20$ bp with a minimum of $90 \%$ identity. To improve sequence identity of the primer with the viral variants, degenerates 
bases were inserted where needed. To improve binding efficiency degenerate bases were not added to the last 3 nucleotides at the $3^{\prime}$ end of the primer and where possible primers had C's or G's at the 3' base.

\section{JFH-1 RNA T7 transcripts}

T7 RNA transcripts for full-length cell culture derived $\mathrm{HCV}$ genotype 2a variant, JFH-1, were generated as previously described [18].

\section{RNA concentration by ultracentrifugation}

For concentration of HCV from plasma samples, 0.5$1 \mathrm{ml}$ of plasma was thawed and centrifuged at $1,500 \mathrm{~g}$ for $10 \mathrm{~min}$ at $4{ }^{\circ} \mathrm{C}$. Supernatants were transferred and centrifuged at $120,000 \mathrm{~g}$ for $1.5 \mathrm{~h}$ at $4{ }^{\circ} \mathrm{C}$ after which the pellet was re-suspended in $140 \mu \mathrm{l}$ of $1 \times$ PBS. Viral RNA was then extracted from the sample as outlined below.

\section{RNA extraction}

Viral RNA was extracted from $140 \mu \mathrm{l}$ of plasma using the QIAmp Viral RNA kit according to manufacturers' instructions (Qiagen, Chadstone Centre, Vic, Australia), with the following modifications: Ambion ${ }^{\circ}$ linear acrylamide (5 $\mu \mathrm{g} /$ extraction, Life Technologies) was used instead of the carrier RNA provided in the kit; sample lysis was performed by inverting tubes instead of vortexing; and the speed of centrifugation was reduced to $3,421 \mathrm{~g}$ for all steps except the final wash which was carried out at $6,082 \mathrm{~g}$. Finally, RNA was eluted in $50 \mu \mathrm{l}$ of RNA Storage Solution $(1 \mathrm{mM}$ sodium citrate $\mathrm{pH}$ 6.4, Life Technologies) and stored at $-80^{\circ} \mathrm{C}$.

\section{Reverse transcription}

Near full-length HCV cDNA was synthesized from viral RNA using the SuperScript III (SIII) First-Strand Synthesis
System (Life Technologies) and a pan-genotype primer (oligo $\mathrm{dA}_{20}$, Table 1). Before commencing reversetranscription (RT), $7 \mu \mathrm{l}$ of RNA, $1 \mu \mathrm{l}$ of $10 \mu \mathrm{M}$ primer and $1 \mu \mathrm{l}$ of $10 \mathrm{mM}$ dNTPs (Promega, Alexandria, NSW, Australia) were mixed and incubated in a thermocycler (T100 ${ }^{\text {mi }}$ BioRad, Gladesville, NSW, Australia) at $65{ }^{\circ} \mathrm{C}$ for 5 mins and then placed immediately on ice for $1 \mathrm{~min}$. RT was then initiated with the addition of RT reaction mix to a $20 \mu \mathrm{l}$ final volume at a final concentration $1 \mathrm{x}$ RT buffer, $5 \mathrm{mM} \mathrm{MgCl}_{2}, 1 \mathrm{M}$ Betaine (Sigma, Sydney, NSW, Australia), $1 \mu \mathrm{l}$ of RNAseOUT (Life Technologies) and 9 $\mathrm{U}$ of SIII RT. Cycling conditions were $49{ }^{\circ} \mathrm{C}$ for $65 \mathrm{~min}$, followed by $85{ }^{\circ} \mathrm{C}$ for $5 \mathrm{~min}$. Two units of RNaseH (Life Technologies) were then added to each reaction before a final incubation at $37^{\circ} \mathrm{C}$ for 20 mins. cDNA samples were held at $12{ }^{\circ} \mathrm{C}$ before proceeding to the PCR reaction.

For optimisation experiments, the yield of near fulllength amplicons was compared between two different SuperScript enzymes II and III (as above) (Invitrogen). For the SII enzyme the RT reaction was performed as described above, except the SuperScript II buffer and SuperScript II enzyme was substituted into the assay. JFH-1 RNA was used as template.

\section{Comparison of different polymerase enzymes for efficient near full-length HCV amplification}

Using full-length JFH-1 cDNA as template, transcribed as described above, two different polymerase combinations were tested for their efficiency in amplifying near full-length genome and a $4 \mathrm{~kb}$ fragment from the $5^{\prime}$ end of the HCV genome in a single round. Primers KY80 and vir45a (Table 1) were used for near full-length amplification, while vir45a was replaced by hep344 [11] for the $4 \mathrm{~kb}$ fragment. The two enzymes tested in parallel were KlenTaq LA (Clontech) and KlenTaq DNA

Table 1 Primers for near full-length HCV amplification

\begin{tabular}{|c|c|c|c|c|c|c|c|}
\hline Region & Round & Sense & GT & Primer name & Sequence $\left(5^{\prime}-3^{\prime}\right)^{\mathrm{a}}$ & Genome binding position ${ }^{b}$ & Published \\
\hline 3'UTR & RT & - & All & vir7 & AAAAAAAAAAAAAAAAAAAA & $9418-9486$ & [13] \\
\hline \multirow[t]{7}{*}{$5^{\prime}$ UTR-NS5B } & \multirow[t]{7}{*}{ Outer } & + & All & KY80 & GCAGAAAGCGTCTAGCCATGGCGT & $68-91$ & [28] \\
\hline & & - & 1 & Vir45a & CCAGCGGGGYCGGGCVYGAGACA & $9262-9314$ & Unpublished \\
\hline & & - & 2 & hep323 & GGAGTGTASCTARTGTGTGCCGCT & $9378-9401$ & [11] \\
\hline & & - & 3 & hep234b & TGGAGTGTTATCYTACCAGC & 9378-9397 & {$[11]$} \\
\hline & & - & 4 & GEN4.R1 & TCGGGCAYGRGACAYGCTGTGATAAATG & $9278-9305$ & [11] \\
\hline & & - & 5 & GEN5.R1 & TCGGGCACGGGACATGCTGTGATAAATG & $9278-9305$ & Unpublished \\
\hline & & - & 6 & Vir65 & CGRGCCYGGGACACGCTGTG & 9285-9304 & Unpublished \\
\hline \multirow[t]{4}{*}{$5^{\prime} U T R-N S 5 B$} & \multirow[t]{4}{*}{ Inner } & + & All & hep21b & GAGTGTYGTRCAGCCTCCAGG & $98-118$ & [20] \\
\hline & & - & $1,2,3,6$ & hep296 & CGGGCAYGAGACASGCTGTGATAWATGTC & 9276-9304 & [11] \\
\hline & & - & 4 & GEN4.R2 & TCTCCCCCGCCRGCGCCYACCGTRAACC & $9250-9277$ & Unpublished \\
\hline & & - & 5 & GEN5.R2 & TCCCCCCCGCCRGCGCCAACGGTRAACC & $9250-9277$ & Unpublished \\
\hline
\end{tabular}

${ }^{\mathrm{a}}$ For degenerate primers, $\mathrm{B}=\mathrm{C}$ or $\mathrm{G}$ or $\mathrm{T}, \mathrm{H}=\mathrm{A}$ or $\mathrm{C}$ or $\mathrm{T}, \mathrm{M}=\mathrm{A}$ or $\mathrm{C}, \mathrm{N}=\mathrm{A}$ or $\mathrm{C}$ or $\mathrm{G}$ or $\mathrm{T}, \mathrm{R}=\mathrm{A}$ or $\mathrm{G}, \mathrm{S}=\mathrm{C}$ or $\mathrm{G}, \mathrm{W}=\mathrm{A}$ or $\mathrm{T}, \mathrm{V}=\mathrm{A}$ or $\mathrm{C}$ or $\mathrm{G}, \mathrm{D}=\mathrm{A}$ or $\mathrm{G}$ or $\mathrm{T}, \mathrm{Y}=\mathrm{C}$ or $\mathrm{T}$

${ }^{\mathrm{b}}$ Genome binding position with reference to HCV GT1a strain, H77, GenBank accession AF009606 
polymerase (AB Peptides, St. Louis, MO) that was used at a ratio of 2 to 1 with $p f u$ DNA polymerase (Stratagene, La Jolle, CA). The reaction conditions of the KlenTaq LA are detailed in the next paragraph. The reaction conditions for the KlenTaq/pfu mix were performed as described by Zhang et al. [13] with the exception that the PCR cycling conditions were the same as those performed with the KlenTaq LA reaction, as described below.

\section{PCR of near full-length HCV genome}

First round PCR was performed using $5 \mu \mathrm{l}$ of $\mathrm{cDNA}$ in a $50 \mu \mathrm{l}$ PCR reaction containing $1 \times$ KlenTaq LA buffer (Clontech), 1.2 M betaine, $200 \mu \mathrm{M}$ of each dNTP, $0.2 \mu \mathrm{M}$ of the forward primer KY80, $0.2 \mu \mathrm{M}$ of the genotype specific reverse primer (Table 1) and $1 \mathrm{U}$ of KlenTaq LA enzyme. PCR was performed at $94{ }^{\circ} \mathrm{C}$ for $2 \mathrm{~min}$, 10 cycles at $94{ }^{\circ} \mathrm{C}$ for $30 \mathrm{~s}, 55^{\circ} \mathrm{C}$ for $20 \mathrm{~s}$, and $68^{\circ} \mathrm{C}$ for $11 \mathrm{~min}$, followed by an additional $20-25$ cycles at $94{ }^{\circ} \mathrm{C}$ for $30 \mathrm{~s}, 57^{\circ} \mathrm{C}$ for $20 \mathrm{~s}$, and $68{ }^{\circ} \mathrm{C}$ for $10: 30 \mathrm{~min}(+20 \mathrm{~s} /$ cycle), with a final extension for $5 \mathrm{~min}$ at $68{ }^{\circ} \mathrm{C}$.

The nested round of PCR was performed with $5 \mu \mathrm{l}$ of first round product in a $50 \mu \mathrm{l}$ reaction as described for the first round, except $0.2 \mu \mathrm{M}$ of hep21b was used as the forward primer and $0.2 \mu \mathrm{M}$ of a nested genotypespecific reverse primer (Table 1). PCR was performed at $94{ }^{\circ} \mathrm{C}$ for $2 \mathrm{~min}, 10$ cycles at $94{ }^{\circ} \mathrm{C}$ for $30 \mathrm{~s}, 58{ }^{\circ} \mathrm{C}$ for $20 \mathrm{~s}$, and $68{ }^{\circ} \mathrm{C}$ for $10: 30 \mathrm{~min}$, followed by an additional 20-25 cycles at $94{ }^{\circ} \mathrm{C}$ for $30 \mathrm{~s}, 60{ }^{\circ} \mathrm{C}$ for $20 \mathrm{~s}$, and $68{ }^{\circ} \mathrm{C}$ for 10:30 $\mathrm{min}(+20 \mathrm{~s} / \mathrm{cycle})$, and then followed by a final extension for $5 \mathrm{~min}$ at $68{ }^{\circ} \mathrm{C}$.

Following positive identification of a band of the correct size, which was approximately 9206 bp (according to HCV GT1a strain H77, GenBank accession AF009606) (Additional file 1: Figure S1), the products were purified using the Agencourt AMPure XP beads (Beckman Coulter, Lane Cove, NSW, Australia) according to the manufacturers instructions, eluted in nuclease-free water and stored at $-80 \mathrm{C}$.

\section{Real-time nested PCR}

HCV RNA was quantified by real-time PCR using a BioRad MyiQ Single-Color real-time PCR detection system (Bio-Rad, CA) as described previously [19] with the exception that primers hep21b (Table 1) and hep22 were used [20] and near full-length cDNA generated as described above, was used as template. PCR band intensities were also quantified by densitometry using ImageJ (version 1.46r).

\section{Illumina sequencing}

Libraries were prepared from the amplicon using either the Nextera XT or TruSeq Nano DNA Library Prep Kits (Illumina) before sequencing using a MiSeq Benchtop
Sequencer generating $2 \times 300$ bp length paired-end reads (v3 kit). NGS reads were aligned using Bowtie 2 [21] implemented in Geneious package version 8 [22]. Reads were aligned against a panel of full-length reference genomes that were obtained from GenBank to represent GTs 1-7 (Fig. 1), and consensus sequences were generated from the aligned contigs. Mixed infection was identified by the generation of multiple contigs against two or more reference genomes. In these situations, a consensus genome sequence was generated for each contig.

\section{PacBio sequencing}

One of the full-length amplicons, RIMM, was selected for generating $>9 \mathrm{~kb}$ sequence reads with PacBio SMRT sequencing. Unique PacBio barcodes were ligated to the amplicon and approximately 0.8 fmoles of the product was then sequenced via 240-min movies on one SMRT Cell using P6-C4 chemistry on a PacBio RS II sequencer (Menlo Park, Pacific Biosciences, California, USA). Genome filtering, assembly and reassembly were performed using tools within SMRT Analysis v2.3. SMRTbell adapter sequences were removed and circular consensus sequence (CCS) reads with a minimum of 2 full passes of the full amplicon (ie. $>18 \mathrm{~kb}$ ) were selected for further analysis. These reads were de novo assembled using VICUNA [23].

\section{Haplotype reconstruction of near full-length HCV quasis- pecies using PacBio SMRT sequencing}

PacBio RS II reads were analysed using haplotype reconstruction analysis, as previously performed [11]. Briefly, haplotype analysis was performed to correct for random technical errors using the software ShoRAH [24]. Only unique haplotypes and their estimated frequency of occurrence within the quasispecies population were reported. Indels identified in homopolymeric regions were manually replaced with the consensus sequence.

\section{Phylogenetic analysis}

The 39 Illumina generated consensus genomes from the 37 clinical samples and the cell culture derived test sample JFH-1 were aligned against representative subtypes from the GT1 to 7 reference genomes with the alignment tool MUSCLE, implemented in Geneious package version 8 [22]. Bootstrapped trees (500 data sets) were constructed using the Neighbour-joining method, also implemented in Geneious package version 8 [22]. Phylogenetic analysis with the PacBio generated haplotypes was performed as described above.

\section{Results and discussion Primer design}

Full-length genome alignments representing all six $\mathrm{HCV}$ GTs were used to assess previously published and novel primer sites for pan-genotypic potential. The previously 


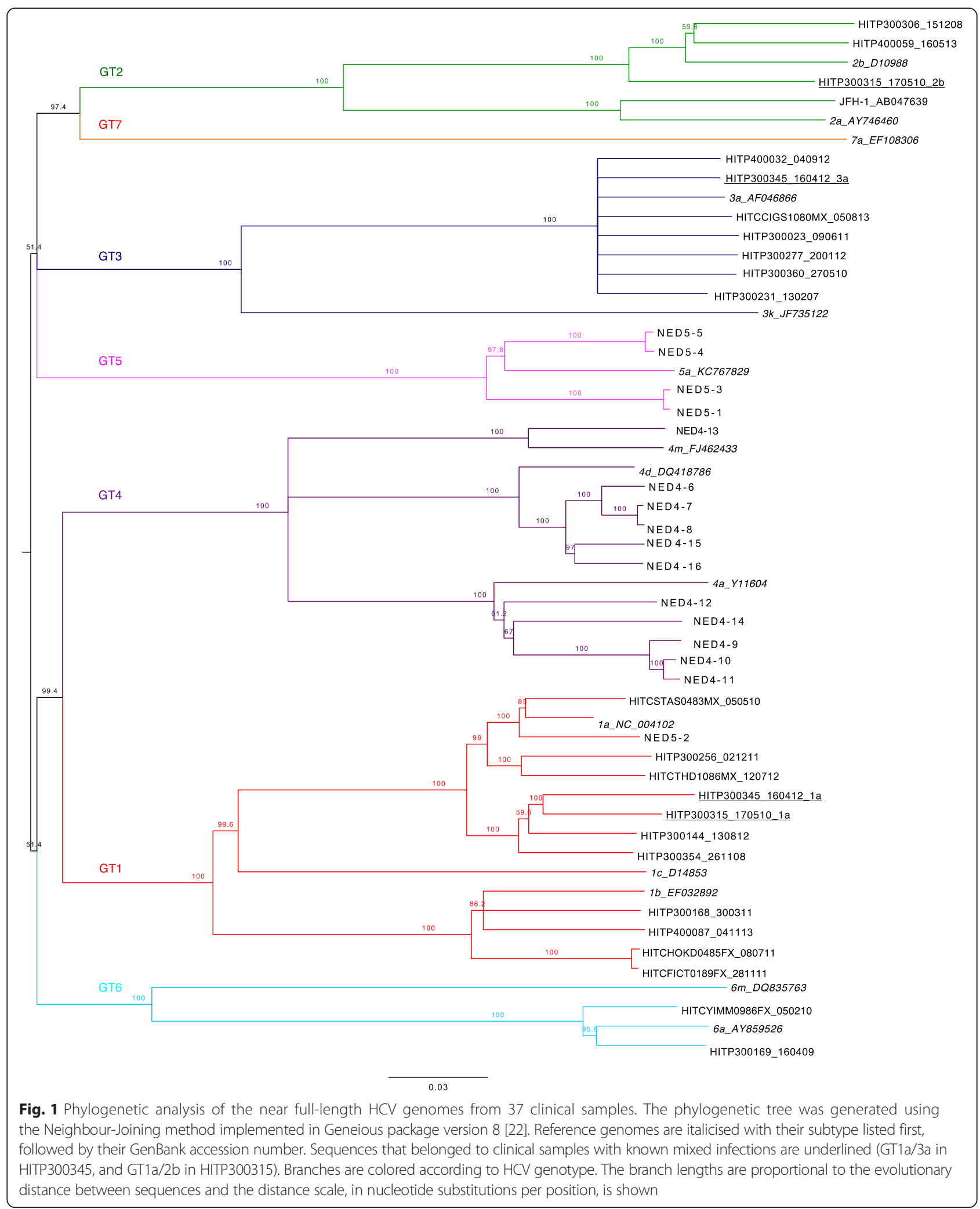

published oligo $\mathrm{dA}_{20}$ primer was selected for the RT step due to its pan-genotypic quality [13]. It was possible to identify pan-genotypic primers for both the forward outer (KY80) and nested (hep21b) primers, but genotype-specific primers were designed for the reverse primer pairs, outer and nested (Table 1). 


\section{RNA extraction optimisation}

For the RNA extraction, the QIAmp viral RNA mini kit was used but several modifications were made to the manufacturer's protocol. These modifications are outlined in detail in the methods section. In brief, the carrier RNA was substituted with $5 \mu \mathrm{g}$ of linear acrylamide, as previously recommended for other RNA viruses, HIV, RSV and WNV [25]. Elution of purified RNA in RNA Storage Solution was essential for optimal results, particularly after long-term storage and repeated freeze-thaw cycles. Successful amplification of near full-length genomes from stored RNA samples was reproducible six months after initial extraction. The centrifugation speeds were also reduced as this was shown to reduce shearing of RNA. Also as successful amplification of the full genome requires intact genomes, mixing of sample by pipetting and vortexing was limited.

\section{cDNA optimisation}

As part of the optimisation process for cDNA generation, RT enzymes, reaction conditions and thermocycling conditions were examined using JFH-1 RNA as template and near full-length amplicon yield as a measure of success. For the RT enzyme analysis, two RT enzymes, SuperScript II and III were compared, with the SIII enzyme generating a 2.6-fold higher yield. For the RT reaction conditions, it has been previously shown that the addition of Betaine at $1 \mathrm{M}$ concentration is optimal in similar assay conditions [26]. Therefore, we tested the effect of Betaine at a final concentration of $1 \mathrm{M}$ on amplicon yield. The cDNA reactions containing $1 \mathrm{M}$ Betaine generated an amplicon with a 9.5-fold increase in yield compared to cDNA conditions with no Betaine (data not shown). In regard to thermocycling conditions, previous reports had indicated optimal cDNA generation of full-length $\mathrm{HCV}$ with an extension time of $2.5 \mathrm{~h}$ with varying extension temperatures [13]. In our study, optimal results were obtained with a constant extension temperature of $49{ }^{\circ} \mathrm{C}$ for 65 mins. It was also noted that more consistent results were obtained when the PCR proceeded immediately after the RT step had finished. Storage of cDNA at either $-20{ }^{\circ} \mathrm{C}$ or $-80{ }^{\circ} \mathrm{C}$ greatly reduced the success rate in generating near full-length amplicons.

\section{PCR optimisation}

For PCR optimisation, two different KlenTaq mixes were compared. The polymerase combination of KlenTaq and $P f u$ at a ratio of 2 to 1 , as outlined by Zhang et al. [13], was compared using either the thermocyling conditions published by Zhang et al. or as recommended for the other commercial KlenTaq mix, KlenTaq LA (see Methods). Both of these conditions were used for the KlenTaq/Pfu mix and compared directly to the commercial polymerase mix of KlenTaq LA (Clontech) that only used the conditions recommended by Clontech. The three different enzyme/assay conditions were tested for amplification efficiency using primer sets that would either generate a $9 \mathrm{~kb}$ or $4 \mathrm{~kb}$ fragment. No amplicons for either the 4 or $9 \mathrm{~kb}$ amplicon were generated following the reaction and cycling conditions nominated by Zhang et al. [13]. For the remaining two enzyme/assay conditions, the yield of the $\sim 9 \mathrm{~kb}$ fragment was increased by 5.5 -fold with the commercial mix, KlenTaq LA compared to the KlenTaq/Pfu mix run with the same cycling conditions (data not shown). A $4 \mathrm{~kb}$ region covering the $5^{\prime}$ end of the genome was also amplified with both polymerase mixes using Clontech's conditions and only a slight increase, 1.3-fold, in amplicon yield of the $4 \mathrm{~kb}$ fragment was observed for the KlenTaq LA polymerase mix. Overall, these results demonstrated the superior performance of the KlenTaq LA mix for the near full-length amplicon, and the kit was adopted for further optimisation.

Generally, the protocol provided with the KlenTaq LA enzyme from Clontech was found to be optimal with the only modification being the addition of Betaine. After the addition of $5 \mu \mathrm{l}$ of cDNA to the PCR assay the final Betaine concentration was $1.3 \mathrm{M}$, which is the recommended concentration for the KlenTaq enzyme.

The efficiency of amplicon generation, in terms of yield of amplicon and reduced non-specific amplification was improved if the RT and PCR primers were aliquoted into small batches with no subsequent freeze/thaw cycles before use. Freeze/thaw rounds of dNTPs did not appear to affect the generation of amplicons.

\section{Detection limit}

To determine the detection limit of the nested PCR assay, a representative cDNA sample for GT1, 2 and 3 was generated. The copy number of near full-length cDNA transcripts was determined by real-time PCR targeting the 5'UTR of the genome. The cDNA samples were then serially diluted and the limit of detection assessed. The assay had a detection limit of 1-3 copies of $\mathrm{HCV}$ near full-length cDNA per reaction. For this assay, we calculated the detection limit using near fulllength cDNA transcripts. This was chosen as there are many independent variables that impact the generation of full-length cDNA transcripts from a $\mathrm{HCV}$ positive plasma sample [27]. For instance, plasma collection protocols, date of collection and storage conditions - particularly in regards to time delays post collection and freeze/thaw occurrence can result in RNA degradation, and subsequently impact the generation of full-length cDNA transcripts. Traditionally, methods used to determine viral RNA genome copies target a small region of the genome and are resilient to RNA degradation and 
therefore not a good indicator of the integrity of full length viral RNA genomes.

\section{Robustness of near full-length amplification}

To test the robustness of the assay on clinical samples, $122 \mathrm{HCV}$ samples with known genotypes were tested for near full-length nested RT-PCR amplification. The viral loads ranged from 317 to $1.59 \times 10^{7} \mathrm{IU} / \mathrm{ml}$. The lowest viral load that was able to generate a near full-length amplicon was $14,853 \mathrm{IU} / \mathrm{ml}$. All 27 samples with a viral load below 14,800 IU/ml failed to amplify (Fig. 2). Another 9 samples with viral loads above 15,000 IU/ml also failed to amplify. Therefore, sensitivity testing indicated that the PCR was robust with $90.5 \%$ of the samples being successfully amplified with a viral load $>14,800 \mathrm{IU} / \mathrm{ml}$ (equivalent to 39,960 copies/ml) (Fig. 2). Analysis of the data stratified by genotype, revealed that GT2b had the lowest success rate of $75.0 \%$, followed by GT3 and GT1 at $87.1 \%$ and $90.9 \%$, respectively (Table 2 ). All remaining genotype samples amplified with a $100 \%$ success rate, although it should be noted that due to these other genotypes being less common in our cohorts their representation in the sample set was lower (Table 2). A representative set of amplicons $(n=37)$ for each genotype were sequenced on the Illumina MiSeq platform. Phylogenetic analysis was used to confirm the success of the assay in amplifying GTs 1-6 (Fig. 1).

\section{Ultracentrifugation}

For samples with low viral loads (less than 15,000 IU/ml) sensitivity of detection could be improved by concentrating the virus from the plasma by ultracentrifugation. In

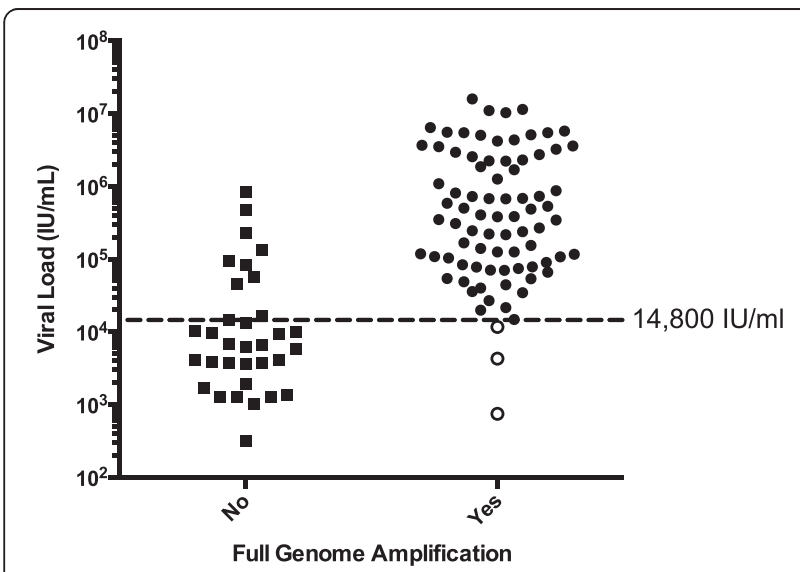

Fig. 2 Sensitivity of the near full-length assay tested on HCV positive clinical samples. The success rate of amplifying near-full length genomes in relation to viral load is shown for 122 samples. Eighty-six of the 95 HCV positive samples with a viral load greater than $14,800 \mathrm{IU} / \mathrm{ml}$ were successfully amplified ( $90.5 \%$ success rate). All 27 samples with a viral load below 14,800 $\mathrm{lU} / \mathrm{ml}$ failed to amplify, however, 10 of these samples were retested following concentration by ultracentrifugation, of which three (30\%) were successfully amplified (hollow circles)
Table 2 Near-full genome amplification success rate by genotype

\begin{tabular}{lll}
\hline HCV GT & \multicolumn{2}{l}{ Number of samples tested (\%) } \\
\cline { 2 - 3 } & Successful & Failed \\
\hline $1 \mathrm{a}$ & $30(90.9)$ & $3(9.1)$ \\
$1 \mathrm{~b}$ & $6(100)$ & $0(0)$ \\
$2 \mathrm{a}^{\mathrm{b}}$ & $1(100)$ & $0(0)$ \\
$2 \mathrm{~b}$ & $6(75)$ & $2(25)$ \\
$3 \mathrm{a}$ & $27(87.1)$ & $4(22.9)$ \\
$4 \mathrm{a}, \mathrm{d}, \mathrm{m}$ & $11(100)$ & $0(0)$ \\
$5 \mathrm{a}$ & $4(100)$ & $0(0)$ \\
$6 \mathrm{a}$ & $3(100)$ & $0(0)$ \\
\hline
\end{tabular}

${ }^{a}$ Only includes samples with viral loads greater than $14,800 \mathrm{lU} / \mathrm{ml}$

${ }^{\mathrm{b}}$ This was cell cultured derived JFH-1 and was not included in the success rate

this study we selected 10 samples that had detectable RNA with the real-time PCR assay that targeted a $175 \mathrm{bp}$ region in the 5'UTR, but could not initially be amplified with the near full-length assay. For these samples, RNA was extracted from $1 \mathrm{ml}$ of plasma after ultracentrifugation. Upon retesting, a near full-length amplicon was generated for 3 of the 10 samples that had previously failed. While ultracentrifugation of larger sample volumes improved the sensitivity of near full-length amplification, we observed that simply increasing the plasma volume from which virus was extracted without ultracentrifugation did not. We speculate that either the additional spin duration, total extraction time or additional PCR inhibitors from the increased plasma volume may account for the reduced RNA extraction efficiency when the plasma volume extracted through the QIAmp column is increased.

\section{Near full-length sequencing on PacBio}

To test whether near full-length sequence reads could be generated from the $\mathrm{HCV}$ amplicon, the sample RIMM was selected for sequencing on the PacBio RS II. A total of 2,664 reads had a minimum of two full passes of the $9.2 \mathrm{~kb}$ amplicon (>18 kb in length) and were used for further analysis. The near-full length PacBio reads were then error corrected via haplotype reconstruction analysis [11]. This analysis showed 45 distinct variants with the most common having a frequency of occurrence of $11 \%$ (HAP1_0.11, Fig. 3), which was identical to the consensus genome sequence generated from the Illumina data.

The sensitivity of PacBio to detect low frequency mutations was compared to the data generated by Illumina from the same amplicon. Both sequencing platforms detected all 11 SNPs with a frequency greater than 7 \% (data not shown). The PacBio reads after cleaning with ShoRAH only detected $4.2 \%$ (3 of a total of 71) of the SNPs detected with the Illumina platform with a 


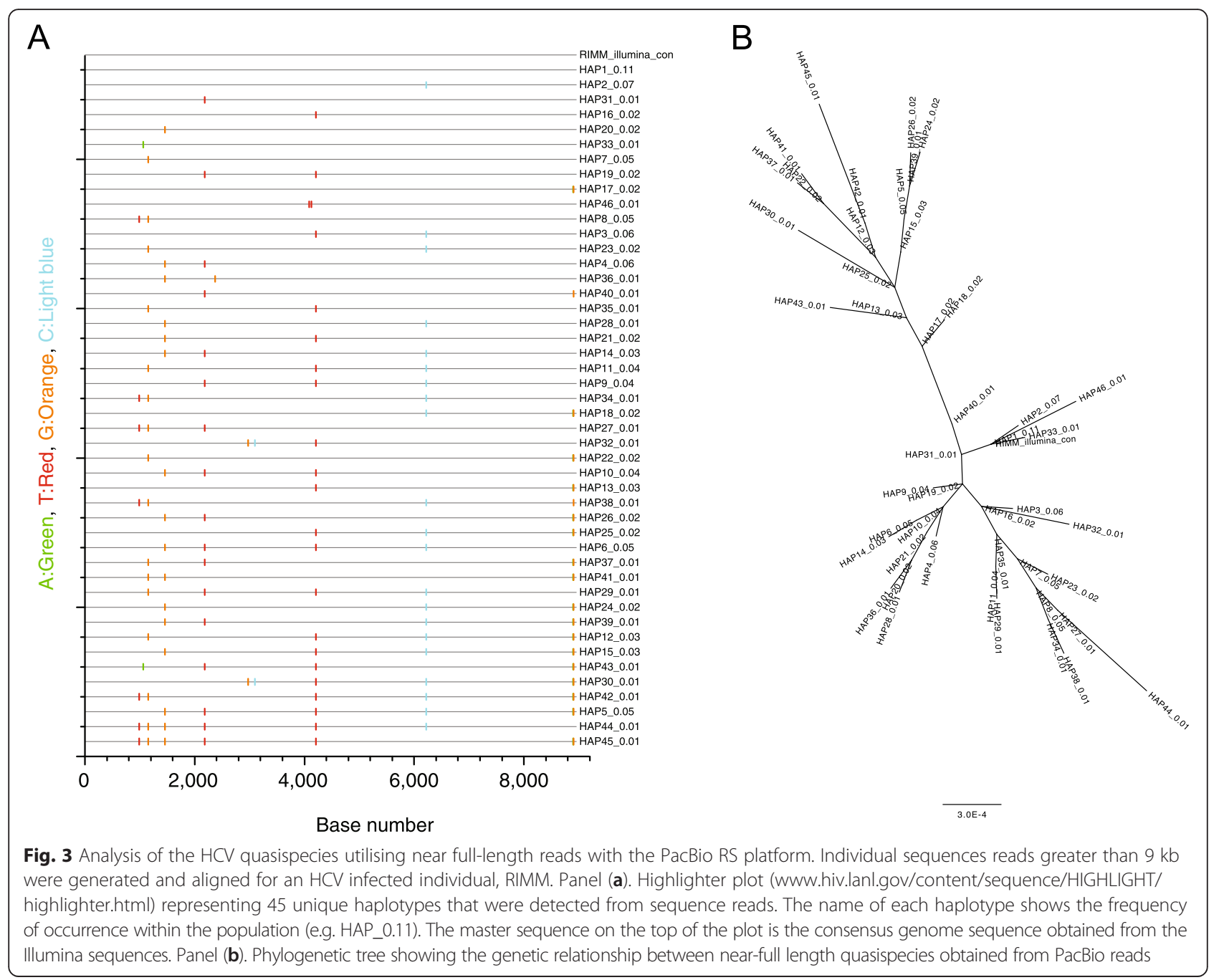

frequency below $7 \%$. However, it should be noted that the genome sequence coverage generated by Illumina was about five-fold higher, with a mean coverage of 11,363 reads/site, respectively and likely accounts for the discrepancy in calling low frequency events.

Phylogenetic analysis of the near-full length haplotypes was performed to understand the relationship of the quasispecies in the acutely infected HCV subject. The analysis depicted the presence of two distinct subpopulations that carry most of their diversity in the structural region of the genome (position 114-2505, Fig. 3a). This analysis confirms the applicability of this approach to perform near-full genome quasispecies analysis.

\section{Multiple infection}

Due to the transmission dynamics of $\mathrm{HCV}$, multiple infections can occur concurrently producing a "co-infection" with two or more $\mathrm{HCV}$ genotypes present at a single time point. In the cohort used in this study the multiple infection rate has been previously reported to be as high as $25 \%$ [17]. We therefore selected two known multiple infection samples, a GT1a/3a and a GT1a/2b sample (HITP300345 and HITP300315, respectively). We multiplexed the reverse primers at equimolar concentrations to test if both genotypes could be simultaneously amplified in the same nRT-PCR reaction. To confirm that this was successful the single amplicon was sequenced on the Illumina platform and the sequence data aligned against both the GT reference sequences (Fig. 4). Sequence reads were successfully mapped to both genotypes from the same sample. The data for subject HITP300345 is shown in Fig. 4 , where $29.6 \%$ and $70.4 \%$ of sequence reads aligning to GT1a and 3a, respectively. Consensus sequences for both genotypes identified in each of the two subjects, HITP300345 and HITP300315 were generated and were clearly shown by phylogenetic analysis to belong to two separate genotypes (Fig. 1). The potential of this assay to 


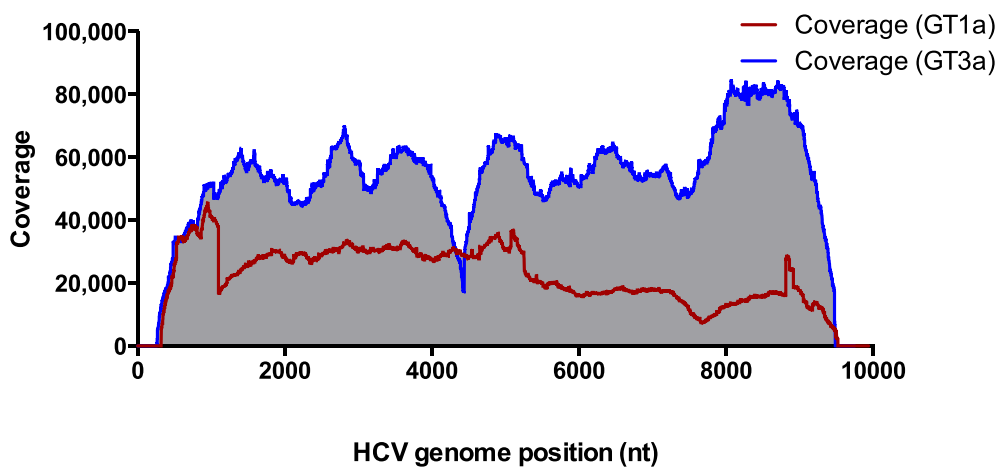

Fig. 4 Subject HITSP300345_160412 was identified as being infected with two HCV genotypes (GT), GT1a and GT3a. The HCV near full-length amplification protocol was adapted to amplify both subtypes in the same reaction and the amplicon was submitted for next generation sequencing with the MiSeq $2 \times 300$ PE chemistry. Analysis of the aligned reads identified two populations, a GT1a and a GT3a population. The presence of two HCV viral populations is shown in a coverage plot stratified by genome position

be used to quantify mixed infection was not assessed. We believe that differences in genotype-specific PCR efficiency due to PCR primer bias and differences in secondary RNA structure would likely result in a semi-quantitative output. In order to quantify co-infections, a RT-PCR targeting a smaller region and with higher sensitivity would be more reliable [17]. The advantage of this assay is that it describes a pipeline for a cost efficient method to obtain fullgenome sequences for phylogenetic and SNP analysis without the need to duplicate PCR assays for multiple genotypes in a single infection.

\section{Conclusions}

In this study we have described a robust assay that can amplify the near full-length genome from all six major HCV GTs. The method can also be simply adapted to detect and sequence multiple infection. The ability to amplify the full genome in a single amplicon as opposed to multiple fragments reduces upstream cost and labour for multiple PCR reactions. Furthermore this method can be easily applied to sequence via multiple platforms, including Sanger sequencing, single genome amplification, short read deep sequencing such as the Illumina and Roche platforms, or the long read platforms, such as PacBio. As the sequence read technology continues to improve, the near-full length sequence data will improve analyses across an array of virological interests, including the ability to perform in-depth within-host evolutionary analysis and also to look at linkage between emerging antiviral resistant sites.

\section{Availability of supporting data}

The GenBank accession numbers for the near-full length genome Illumina generated consensus nucleotide sequences of the samples in Fig. 1 are as follows:
KU871276 to KU871311, KJ437295, KJ437300 and KJ437342.

\section{Additional file}

Additional file 1: Figure S1. Successful amplification of near full-length HCV genomes from multiple genotypes. Amplicons ( 9.2 kb) were run on an agarose gel (0.8\%) and visualized on a Gel Doc molecular imager (Bio-Rad); M represents the DNA marker HyperLadder 1 (Bioline). Lanes 1 to 8 represent GT1a amplicons. Lanes 9 to 11 represent GT1b amplicons. Lanes 12 to 16 represent GT3a amplicons. All amplicons were purified and successfully sequenced on the Illumina platform, including the faintly visible band in lane 7. (PDF $2448 \mathrm{~kb}$ )

\section{Abbreviations}

DAA: direct acting antiviral; GT: genotype; HCV: hepatitis C virus; NGS: next generation sequencing; NS: non-structural; PacBio: Pacific Biosciences; PCR: polymerase chain reaction; RT: reverse transcription; SMRT: single molecule real time.

\section{Competing interests}

AT, ML, SO and CH are full time employees of Pacific Biosciences, a company commercializing SMRT sequencing technologies. Pacific Biosciences provided the PacBio sequencing free of charge. The authors declare that the research was conducted in the absence of any commercial or financial relationships that could be construed as a potential conflict of interests.

\section{Authors' contributions}

RAB and $A E$ designed and conducted experiments, and wrote the manuscript. RAB, AE, CR, MRP, MW and SMM performed experiments. ARL, $\mathrm{LM}$ and JS provided samples. BB-S and FL assisted with sequence analysis. AT, ML, SO and $\mathrm{CH}$ performed the PacBio sequencing. All authors have read and approved the manuscript.

\section{Acknowledgements}

This work was funded by NHMRC project grant, 1042090. ARL and RAB are supported by National Health and Medical Council of Australia (NHMRC) Fellowships (RG121994, 1084706).

\section{Author details}

${ }^{1}$ School of Medical Sciences, Faculty of Medicine, University of New South Wales, Sydney 2052, Australia. ${ }^{2}$ Department of Medical Microbiology, Section of Clinical Virology, Academic Medical Center, Public Health Service, Amsterdam, The Netherlands. ${ }^{3}$ The Kirby Institute, University of New South Wales, Sydney, Australia. ${ }^{4}$ Pacific Biosciences, Menlo Park, CA, USA. 
Received: 22 October 2015 Accepted: 8 March 2016

Published online: 17 March 2016

\section{References}

1. Mohd Hanafiah K, Groeger J, Flaxman AD, Wiersma ST. Global epidemiology of hepatitis $C$ virus infection: new estimates of age-specific antibody to HCV seroprevalence. Hepatology. 2013:57(4):1333-42.

2. Scheel TK, Rice CM. Understanding the hepatitis $C$ virus life cycle paves the way for highly effective therapies. Nat Med. 2013;19(7):837-49.

3. Bartenschlager R, Lohmann V. Replication of hepatitis C virus. J Gen Virol. 2000;81(7):1631-48.

4. Smith DB, Bukh J, Kuiken C, Muerhoff AS, Rice CM, Stapleton JT, Simmonds $P$. Expanded classification of hepatitis $C$ virus into 7 genotypes and 67 subtypes: updated criteria and genotype assignment web resource. Hepatology. 2014:59(1):318-27.

5. Simmonds P, Bukh J, Combet C, Deleage G, Enomoto N, Feinstone S, Halfon P, Inchauspe G, Kuiken C, Maertens G, et al. Consensus proposals for a unified system of nomenclature of hepatitis $C$ virus genotypes. Hepatology. 2005:42(4):962-73.

6. Messina JP, Humphreys I, Flaxman A, Brown A, Cooke GS, Pybus OG, Barnes E. Global distribution and prevalence of hepatitis $C$ virus genotypes. Hepatology. 2015;61(1):77-87.

7. Murphy DG, Willems B, Deschenes M, Hilzenrat N, Mousseau R, Sabbah S. Use of sequence analysis of the NS5B region for routine genotyping of hepatitis $C$ virus with reference to $C / E 1$ and $5^{\prime}$ untranslated region sequences. J Clin Microbiol. 2007:45(4):1102-12.

8. Fonseca-Coronado S, Escobar-Gutierrez A, Ruiz-Tovar K, Cruz-Rivera MY, Rivera-Osorio P, Vazquez-Pichardo M, Carpio-Pedroza JC, Ruiz-Pacheco JA, Cazares F, Vaughan G. Specific detection of naturally occurring hepatitis C virus mutants with resistance to Telaprevir and Boceprevir (Protease Inhibitors) among treatment-naive infected individuals. J Clin Microbiol. 2012;50(2):281-7.

9. Lauck M, Alvarado-Mora MV, Becker EA, Bhattacharya D, Striker R, Hughes AL, Carrilho FJ, O'Connor DH, Pinho JR. Analysis of hepatitis $\mathrm{C}$ virus intrahost diversity across the coding region by ultradeep pyrosequencing. J Virol. 2012;86(7):3952-60.

10. Bretana NA, Boelen L, Bull R, Teutsch S, White PA, Lloyd AR, Luciani F, investigators HI-p. Transmission of hepatitis $C$ virus among prisoners, Australia, 2005-2012. Emerg Infect Dis. 2015;21(5):765-74

11. Bull RA, Luciani F, McElroy K, Gaudieri S, Pham ST, Chopra A, Cameron B, Maher L, Dore GJ, White PA, et al. Sequential bottlenecks drive viral evolution in early acute hepatitis C virus infection. PLoS Pathog. 2011;7(9): e1002243.

12. Lamoury FM, Jacka B, Bartlett S, Bull RA, Wong A, Amin J, Schinkel J, Poon AF, Matthews GV, Grebely J, et al. The Influence of hepatitis C virus genetic region on phylogenetic clustering analysis. PLoS One. 2015;10(7):e0131437.

13. Zhang EZ, Bartels DJ, Frantz JD, Seepersaud S, Lippke JA, Shames B, Zhou Y, Lin C, Kwong A, Kieffer TL. Development of a sensitive RT-PCR method for amplifying and sequencing near full-length HCV genotype 1 RNA from patient samples. Virol J. 2013;10(1):53.

14. Fan $X, X u Y$, Di Bisceglie AM. Efficient amplification and cloning of near full-length hepatitis $C$ virus genome from clinical samples. Biochem Biophys Res Commun. 2006;346(4):1163-72

15. Hedskog C, Chodavarapu K, Ku KS, Xu S, Martin R, Miller MD, Mo H, Svarovskaia E. Genotype and subtype independent full genome sequencing assay for hepatitis C virus. J Clin Microbiol. 2015:53(7):2049-59.

16. Teutsch S, Luciani F, Scheuer N, McCredie L, Hosseiny P, Rawlinson W, Kaldor J, Dore GJ, Dolan K, Ffrench R, et al. Incidence of primary hepatitis C infection and risk factors for transmission in an Australian prisoner cohort. BMC Public Health. 2010;10:633.

17. Pham ST, Bull RA, Bennett JM, Rawlinson WD, Dore GJ, Lloyd AR, White PA. Frequent multiple hepatitis $C$ virus infections among injection drug users in a prison setting. Hepatology. 2010;52(5):1564-72.

18. Kato T, Date T, Murayama A, Morikawa K, Akazawa D, Wakita T. Cell culture and infection system for hepatitis C virus. Nat Protoc. 2006;1 (5):2334-9.

19. Tu ET, Bull RA, Greening GE, Hewitt J, Lyon MJ, Marshall JA, Mclver CJ, Rawlinson WD, White PA. Epidemics of gastroenteritis during 2006 were associated with the spread of norovirus Gll.4 variants 2006a and 2006b. Clin Infect Dis. 2008:46(3):413-20.
20. White PA, Zhai X, Carter I, Zhao Y, Rawlinson WD. Simplified hepatitis C virus genotyping by heteroduplex mobility analysis. J Clin Microbiol. 2000;38(2):477-82

21. Langmead B, Salzberg SL. Fast gapped-read alignment with Bowtie 2. Nat Methods. 2012;9(4):357-9.

22. Kearse M, Moir R, Wilson A, Stones-Havas S, Cheung M, Sturrock S, Buxton S, Cooper A, Markowitz S, Duran C, et al. Geneious Basic: an integrated and extendable desktop software platform for the organization and analysis of sequence data. Bioinformatics. 2012:28(12):1647-9.

23. Yang X, Charlebois P, Gnerre S, Coole MG, Lennon NJ, Levin JZ, Qu J, Ryan EM, Zody MC, Henn MR. De novo assembly of highly diverse viral populations. BMC Genomics. 2012;13:475.

24. Zagordi O, Bhattacharya A, Eriksson N, Beerenwinkel N. ShoRAH: estimating the genetic diversity of a mixed sample from next-generation sequencing data. BMC Bioinformatics. 2011;12:119.

25. Malboeuf CM, Yang X, Charlebois P, Qu J, Berlin AM, Casali M, Pesko KN, Boutwell $C L$, DeVincenzo JP, Ebel GD, et al. Complete viral RNA genome sequencing of ultra-low copy samples by sequence-independent amplification. Nucleic Acids Res. 2013;41(1), e13.

26. Picelli S, Faridani OR, Bjorklund AK, Winberg G, Sagasser S, Sandberg R. Full-length RNA-seq from single cells using Smart-seq2. Nat Protoc. 2014:9(1):171-81.

27. Halfon P, Khiri H, Gerolami V, Bourliere M, Feryn JM, Reynier P, Gauthier A, Cartouzou G. Impact of various handling and storage conditions on quantitative detection of hepatitis C virus RNA. J Hepatol. 1996;25(3):307-11.

28. Young KK, Resnick RM, Myers TW. Detection of hepatitis C virus RNA by a combined reverse transcription-polymerase chain reaction assay. J Clin Microbiol. 1993:31(4):882-6.

\section{Submit your next manuscript to BioMed Central and we will help you at every step:}

- We accept pre-submission inquiries

- Our selector tool helps you to find the most relevant journal

- We provide round the clock customer support

- Convenient online submission

- Thorough peer review

- Inclusion in PubMed and all major indexing services

- Maximum visibility for your research

Submit your manuscript at www.biomedcentral.com/submit 